\title{
Molecular mechanisms of cellular proliferation in acute myelogenous leukemia by leptin
}

\author{
JU YOUNG KIM ${ }^{1 *}$, HYUN KI PARK ${ }^{1 *}$, JIN SUN YOON ${ }^{1}$, SEO JU KIM ${ }^{1}$, EUN SHIL KIM ${ }^{1}$, SUNG HEON SONG ${ }^{2}$, \\ JUNG HYE CHOI ${ }^{2}$, BYOUNG KOOK KIM ${ }^{1}$, BYOUNG BAE PARK ${ }^{2}$ and YOUNG YIUL LEE ${ }^{1,2}$ \\ ${ }^{1}$ Laboratory of Hematopoiesis and Hematologic Malignancy, Cancer Research Institute, Seoul National University, \\ College of Medicine; ${ }^{2}$ Department of Internal Medicine, Han Yang University Hospital, Seoul, Korea
}

Received November 23, 2009; Accepted January 26, 2010

DOI: $10.3892 /$ or_00000773

\begin{abstract}
Leptin acts as a growth factor in normal cells as well as in various types of cancer cells. We investigated the effects of leptin on human acute myelogenous leukemia (AML) cells. Leptin stimulated the proliferation of HEL cells through the phosphorylation of STAT3 and ERK1/2. The blocking of STAT3 phosphorylation with the specific inhibitor, AG490, significantly reduced leptin-induced ERK1/2 phosphorylation and cellular proliferation, whereas the blocking of ERK1/2 activation by the specific ERK1/2 inhibitor, PD98059, did not affect the STAT3 phosphorylation or leptininduced proliferation in HEL cells. Furthermore, knockdown of leptin receptor (OB-R) expression with stealth RNA interference (RNAi) reduced the leptin-induced proliferation of HEL cells and also significantly attenuated leptin-induced STAT3 and ERK1/2 activation. These results suggest that leptin promotes AML cell growth by activating STAT3 and MAPK, although not directly dependent on ERK.
\end{abstract}

\section{Introduction}

Leptin, a 16-kDa protein secreted mainly from adipocytes (1), was originally identified as a cytokine that regulates fat metabolism, and defective leptin production has been associated with obesity in humans and animals (2-4). Leptin was found to function, not only in cell survival and antiapoptosis, but was also found to be involved in other physiological roles such as the regulation of hematopoiesis (5),

Correspondence to: Professor Young Yiul Lee or Dr Byoung Bae Park, Department of Internal Medicine, Division of Hematology/Oncology, Han Yang University Hospital, 17 Haeng Dang-dong, Sung Dong-ku, Seoul 133-792, Korea

E-mail: leeyy@hanyang.ac.kr; bbpark@hanyang.ac.kr

${ }^{*}$ Contributed equally

Key words: leptin, human leukemia cells, acute myelogenous leukemia, signal transducer and activator of transcription 3 , extracellular signal-activated kinase $1 / 2$ differentiation (6), angiogenesis (7), immunity (8), the inflammatory response (9), reproduction (10) and insulin secretion (11).

Leptin exerts its actions through its specific receptor which is localized to the cell membrane and is present in a variety of tissues (12). The leptin receptor, OB-R, is a single membranespanning receptor which exhibits sequence similarity with the gp130 signal-transducing component of the interleukin (IL)-6 receptor and leukemia inhibitory factor (LIF) receptor $(13,14)$. The OB-R is alternately spliced into six transcripts with long (OB-Rb) and short (OB-Ra) forms according to the varying lengths of their cytoplasmic tail from the single $d b$ gene (15). Upon leptin binding, OB-R homodimerizes and signals through the phosphorylation of Janus kinase-signal transducer and activator of transcription (JAK-STAT) and mitogen-activated protein kinase and extracellular signalactivated kinase 1/2 (MAPK/ERK1/2) signaling pathways in several cancer cell lines. Other pathways, including phosphatidylinositol-3 kinase (PI3K), are also activated by leptin (16-19).

OB-R isoforms have been detected in many types of cancer cells including leukemia cells. However, expression of the leptin receptor and the associated biologic significance in acute myelogenous leukemia (AML) cells is still poorly understood.

In this study, the relationship between leptin and leptin receptor expression was analyzed in AML cell lines, and the effects of leptin on intracellular signal transduction pathways and AML cell proliferation were investigated.

\section{Materials and methods}

Reagents. Recombinant human leptin was purchased from R\&D Systems (Minneapolis, MN) and dissolved according to the manufacturer's instructions. PD98059 and AG490 were purchased from Calbiochem (San Diego, CA), dissolved in DMSO (Sigma Chemical, St. Louis, MO) and stored at $-20^{\circ} \mathrm{C}$ until used. The DMSO concentration was $0.001 \%$, and the same concentration was used as vehicle. Lipofectamine ${ }^{\mathrm{TM}}$ reagent, Lipofectamine 2000, was purchased from Invitrogen (Gergy Pontoise, France).

Cell culture. The human leukemia cell lines used in this study, HEL, HL60, K562, KCL22, KG-1, Mego1, ML1, NB4 
and U937, were kindly provided by Dr H.P. Koeffler (UCLA, Cedars-Sinai Medical Center, Los Angeles, CA, USA). All cell lines were maintained in RPMI-1640 medium (GibcoBRL, Gaithersburg, MD, USA) supplemented with $10 \%$ (vol/vol) fetal bovine serum (FBS) (Hyclone Labs, Inc., Logan, UT, USA), $100 \mathrm{U} / \mathrm{ml}$ penicillin and $100 \mu \mathrm{g} / \mathrm{ml}$ streptomycin (Sigma Chemical). Cells were maintained in a humidified atmosphere in $5 \% \mathrm{CO}_{2}$ at $37^{\circ} \mathrm{C}$, and the culture medium was changed every 3-4 days. For leptin and other treatments, cells were serum-starved for $24 \mathrm{~h}$ and then treated with leptin (at the indicated doses), OB-R RNAi (100 nM), PD98059 (MEK inhibitor, $25 \mu \mathrm{M}$ ) or AG490 (STAT inhibitor, $50 \mu \mathrm{M})$ for the indicated times.

$R T-P C R$. Total RNA was isolated with Tri reagent (Molecular Research Center, Inc.), and cDNAs were synthesized with $1 \mu \mathrm{g}$ of total RNA using the RNA PCR Kit (Takara Bio Inc.). Primers were designed with the aid of primer designing software using the human leptin receptor, the huOB-Rb (GeneBank accession no. U43168) complementary DNA (cDNA) sequence and the huOB-Ra (GeneBank accession no.U52914) sequence obtained from Entrez. These were designed either to detect the presence of any of the leptin receptor isoforms (common sequence from the extracellular domain) or to be specific to the long (huOB-Rb) or short isoform (huOB-Ra). The expected product lengths were $489 \mathrm{bp}$ for the common receptor primers, $481 \mathrm{bp}$ for the long receptor primers and $200 \mathrm{bp}$ for the short isoform. The primer sequences were as follows: human leptin receptor (common), F 5'-CTTTCCACTGTTGCTTTCGG-3'; R 5'-TCTGTGATT CCATATGCAAACC-3'; huOB-Rb (long), F 5'-CCATGA TCATTTTATCCCCA-3'; R 5'-GTCACTAATACAAACA GAACCC-3'; and huOB-Ra (short), F 5'-TTGTGCCAGTA ATTATTTCCTCTT-3'; R, 5'-AGTTGGCACATTGGGTTC AT-3'. Polymerase chain reaction was performed for 40 cycles using a 60 -sec denaturation step at $94^{\circ} \mathrm{C}$, a 60 -sec annealing step at $55^{\circ} \mathrm{C}$, and a 90 -sec extension step at $72^{\circ} \mathrm{C}$. The product ( $5 \mu 1$ ) was loaded onto agarose gel, and the fluorescence of the ethidium bromide-stained band was recorded.

Cell proliferation assay. The proliferative effect of leptin on human leukemia cells was determined by measuring the 3 (4,5-dimethylthiazol-2-yl)-2,5-diphenyltetrazolium bromide (MTT) (Sigma) dye absorbance of living cells. Briefly, cells $\left(10^{4} /\right.$ well) were seeded in 96-well plates and exposed to leptin at different concentrations for 24,48 and $72 \mathrm{~h}$. The cells were subsequently incubated with $50 \mu 1$ of MTT solution $(2 \mathrm{mg} / \mathrm{ml}$ in PBS), and the plates were incubated for $4 \mathrm{~h}$ at $37^{\circ} \mathrm{C}$. After removal of the MTT solution, $200 \mu 1$ of DMSO was added to the cells. The plates were shaken for $30 \mathrm{~min}$ at room temperature, and the absorbance was measured at $540 \mathrm{~nm}$ on a scanning multi-well spectrophotometer.

Western blot analysis. Cells were washed with PBS and suspended in an extraction buffer (Intron Biotechnology, Korea) on ice for $15 \mathrm{~min}$. Lysates were cleared by centrifugation at 13,000 rpm for $20 \mathrm{~min}$. Equal amounts of cell extracts $(20 \mu \mathrm{g})$ were resolved on $8-10 \%$ SDS-PAGE gels, transferred onto a nitrocellulose membrane and probed with $\sim 0.1 \mu \mathrm{g} / \mathrm{ml}$ of goat anti-human OB-R (Santa Cruz); rabbit

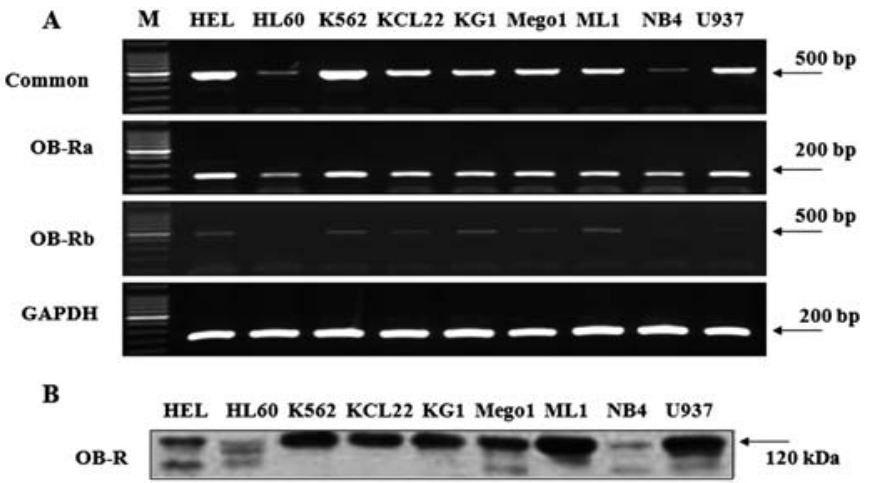

Figure 1. OB-R isoforms detected in human leukemia cell lines. (A) Messenger RNA was detected by reverse transcription-PCR. GAPDH mRNA was amplified as an internal control. (B) Detection of OB-R protein was performed by Western blot analysis as described in Materials and methods. The experiment was performed three times with similar results.

anti-c-myc (Santa Cruz); rabbit anti-human STAT1, 3, 5, 6; phospho-STAT1, 3, 5, 6; ERK1/2; phospho-ERK1/2; phospho-MEK1/2; phospho-p90RSK; phospho-Elk-1; AKT; phospho-AKT; phospho-PTEN (Cell Signaling Technology); and mouse anti-human $\alpha$-tubulin (Sigma Chemical) used at 1:1,000 dilutions and incubated at $4^{\circ} \mathrm{C}$ overnight. The membrane was then incubated with the appropriate secondary antibody $(1: 2,000$ dilution) in $1 \%$ skimmed milk/Tris-based saline with $0.05 \%$ Tween-20 (TBST) for $2 \mathrm{~h}$ at room temperature. The blots were developed by using the West$\mathrm{Zol}^{\mathrm{TM}}$ Western Blot Detection System (Intron Biotechnology, Korea).

RNAi experiment. Stealth RNAi complementary to the OB-R genes (GenBank accession nos. U4368 and U52914; 5'-GGA GCAGCCTTTACTGTTCTGATAT-3') was designed using the Stealth ${ }^{\mathrm{TM}}$ RNA Program from Invitrogen (Cergy Pontoise). Cells were transfected with $100 \mathrm{nM}$ of RNAi and Lipofectamine reagent, Lipofectamine 2000, according to the manufacturer's instructions. The cells were serum-deprived overnight and exposed to $100 \mathrm{ng} / \mathrm{ml}$ of leptin for 2 or $72 \mathrm{~h}$. Transfection efficiency was monitored by RT-PCR with OB-R expression.

Statistical analysis. Data were analyzed using the Student's t-test. Probability values $<0.05$ were considered statistically significant.

\section{Results}

Expression of leptin receptor isoforms in human AML cell lines. Expression of the human leptin receptor was detected in the 9 human leukemia cell lines examined by RT-PCR and Western blotting. Total RNA was extracted from leukemia cells, and RT-PCR was then performed using the primer sets for leptin receptor isoforms. The sequences were as follows: i) a common sequence from the extracellular domain of the human leptin receptor, ii) a sequence exclusive to the long isoform of the leptin receptor $(\mathrm{OB}-\mathrm{Rb})$, iii) a sequence exclusive to the short isoform OB-Ra and standardized using the GAPDH. As shown in Fig. 1A, the mRNA expression 
A

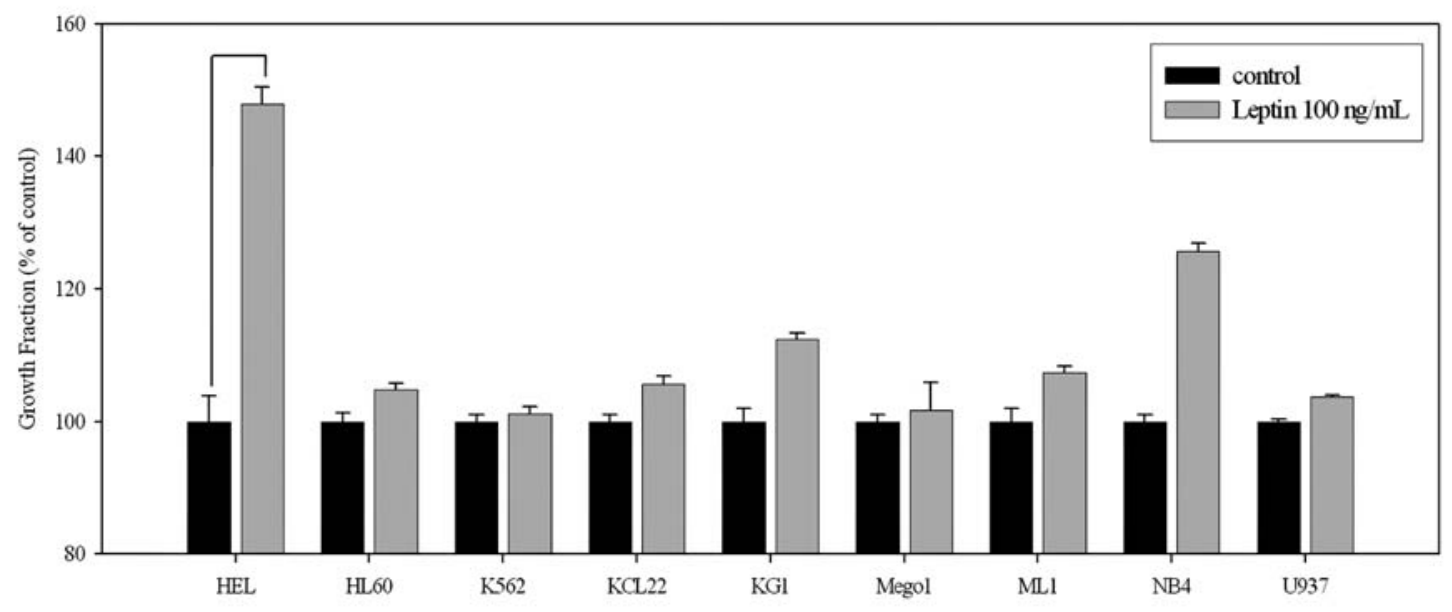

B
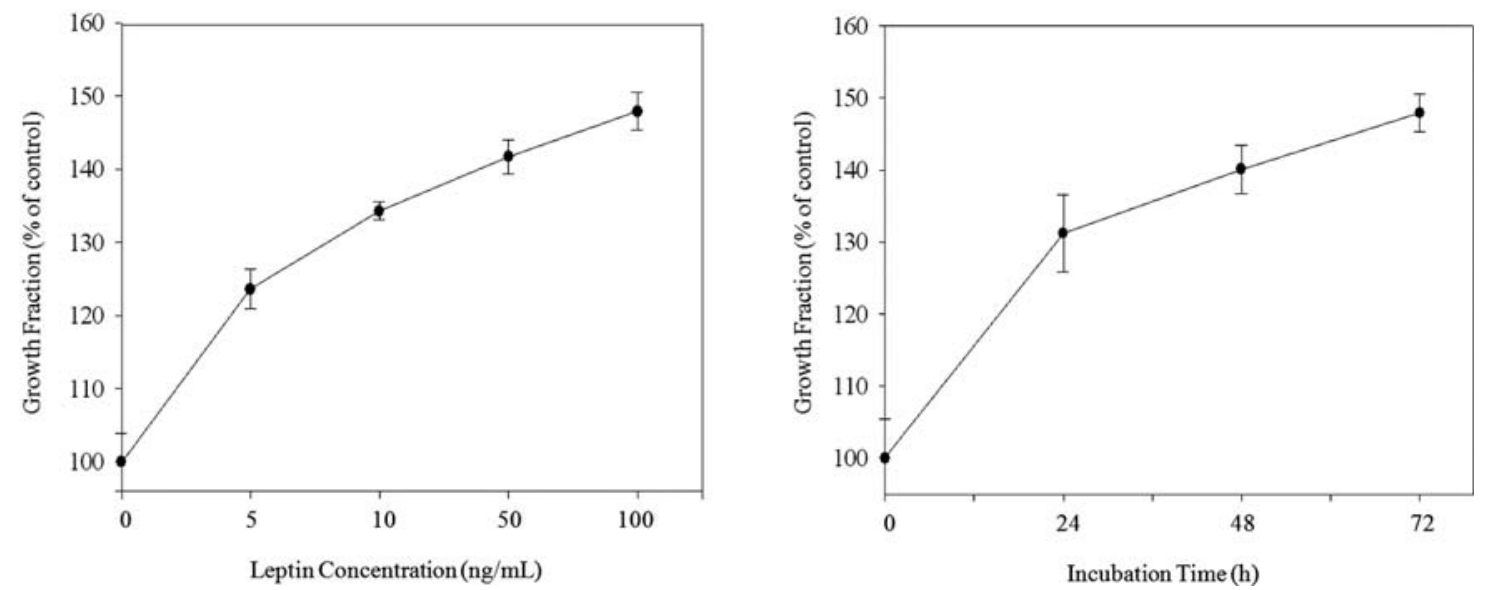

Figure 2. Leptin induces cell proliferation in human leukemia cell lines. (A) Nine human leukemia cell lines were incubated with $100 \mathrm{ng} / \mathrm{ml}$ of leptin for $72 \mathrm{~h}$, and (B) HEL cells were incubated with $0-100 \mathrm{ng} / \mathrm{ml}$ of leptin for 3 days, and colorimetric MTT assays were performed. Bars indicate the means \pm SD; $(\mathrm{P}<0.05)$.

levels of long and short leptin receptors varied among the different cell lines. HL60 and NB4 expressed the lowest level, whereas HEL and K562 expressed the highest level. To further confirm the expression of this receptor, Western blot assay was carried out resulting in a similar expression pattern when compared with RT-PCR (Fig. 1B).

Effect of leptin on cell proliferation in human AML cell lines. In these experiments, 9 human leukemia cell lines were serumstarved and subsequently treated with leptin $(0-100 \mathrm{ng} / \mathrm{ml})$ for $72 \mathrm{~h}$. The effect of leptin treatment on cell proliferation was assessed using the MTT assay. Among the 9 cell lines tested, only HEL cells displayed a significant proliferative response to leptin alone (Fig. 2A). As shown in Fig. 2B, leptin simulated the growth of HEL cells in a time- and dosedependent manner. A significant stimulatory effect in the HEL cells was apparent at $24 \mathrm{~h}$ after treatment with $100 \mathrm{ng} / \mathrm{ml}$ leptin. The proliferative response in the cell lines did not correlate with the level of OB-R expression; e.g., K562 cells exhibited no proliferative response in spite of the high levels of OB-R.

Effect of leptin on STATs and MAPK in HEL cells. To investigate the role of leptin on STATs, MAPK and AKT activation, HEL cells were incubated with leptin $(100 \mathrm{ng} / \mathrm{ml})$ for $0,15,30,60$ and $120 \mathrm{~min}$. As shown in Fig. 3A, STAT3, 5 and 6 phosphorylation was stimulated by leptin in a timeand dose-dependent manner, while the phosphorylation of STAT1 did not changed in the HEL cells after leptin stimulation. In contrast, the total level of STAT1, 3, 5 and 6 did not change, suggesting that the increased STAT3, 5 and 6 phosphorylation was not caused by increased STAT3, 5 and 6 expression. These results indicate that STAT3, 5 and 6 are involved in the cell growth effect by leptin in HEL cells. As shown in Fig. 3B, MEK1/2, ERK1/2, p90RSK and c-myc phosphorylation was stimulated in a time-dependent manner, but the phosphorylation of Elk was not detected after leptin stimulation of HEL cells. These results indicate that leptin induced cell proliferation through the MEK/ERK/p90RSK or c-myc signaling pathway. As shown in Fig. 3C, p-AKT was not detected while expression of p-PTEN was high and total AKT did not change after leptin stimulation of HEL cells. These results indicate that leptin-induced cell proliferation was not mediated via the AKT signaling pathway in HEL cells.

Effect of pharmacologic inhibitors on the proliferative effect of leptin on HEL cells. To investigate whether the STAT3 and ERK1/2 phosphorylation was linked to the cell proliferative effect of leptin, specific inhibitors were used to block STAT3 phosphorylation or ERK1/2 phosphorylation 


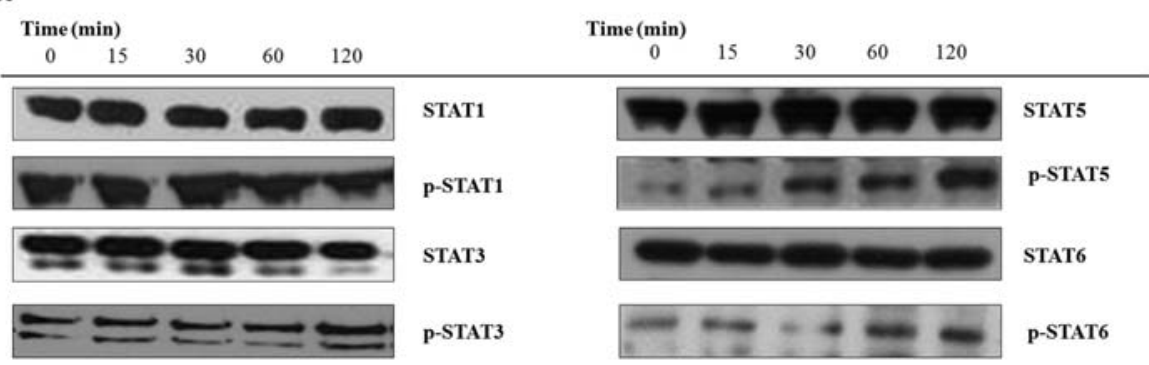

B
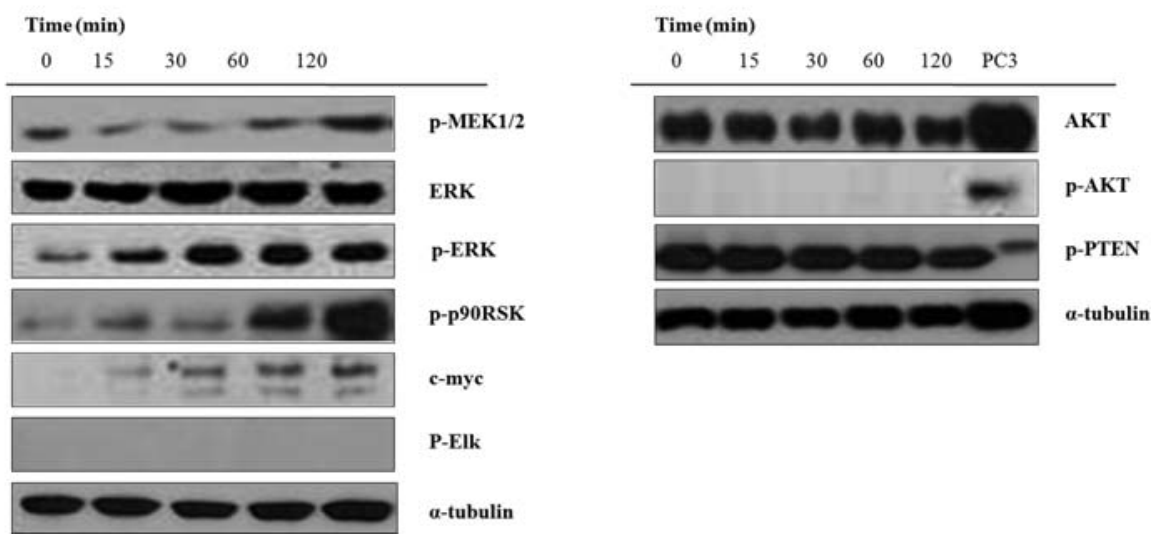

Figure 3. Leptin activates the STATs and MAPK but not AKT in HEL cells. HEL cells were treated with $100 \mathrm{ng} / \mathrm{ml}$ of leptin for the time indicated, and lysates (15-30 $\mu \mathrm{g}$ of protein) were immunoblotted with specific antibodies against the total and phosphorylated (p) form of STATs (A), MAPK (B) and AKT (C).

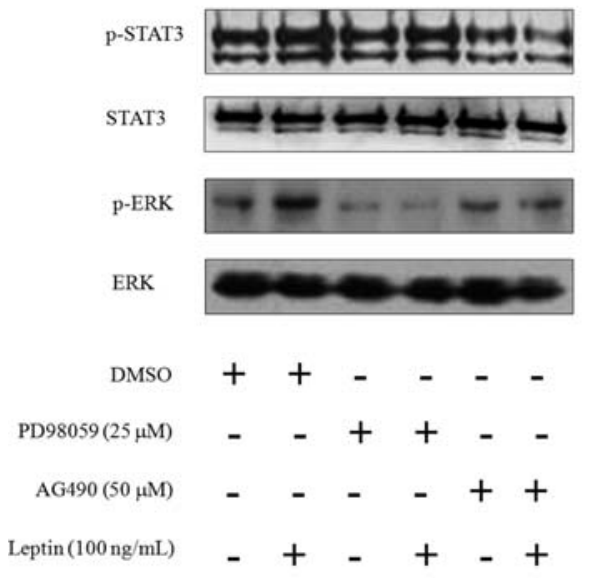

B

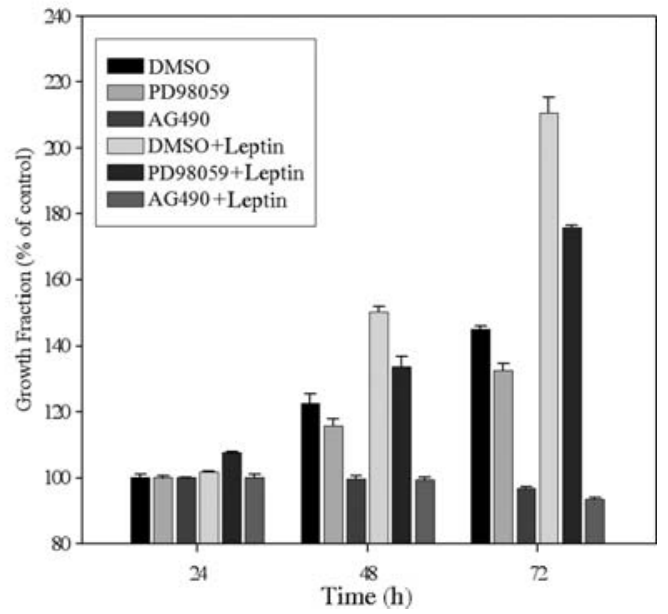

Figure 4. Effect of pharmacologic inhibitors on the proliferative effect of leptin on HEL cells. HEL cells were treated with $100 \mathrm{ng} / \mathrm{ml}$ of leptin for the time indicated, pretreated with PD98059 $(25 \mu \mathrm{M})$ or AG490 $(50 \mu \mathrm{M})$ for $1 \mathrm{~h}$, and then lysates $(15-30 \mu \mathrm{g}$ of protein) were immunoblotted with specific antibodies against the total and phosphorylated (p) form of STAT3 and ERK (A) or colorimetric MTT assays were performed (B); (P<0.05).

without affecting the expression of total STAT3 or ERK1/2, and the cell proliferation was measured upon treatment with leptin using MTT assays in HEL cells. As shown in Fig. 4A, treatment with STAT3 inhibitor AG490 blocked leptininduced phosphorylation of ERK1/2, while the ERK1/2 inhibitor PD98059 had no effect on the leptin-induced phosphorylation of STAT3. Examination of the cell proliferation under these conditions indicated that the blocking of STAT3 phosphorylation significantly reduced the growth stimulation by leptin, while the blocking of ERK1/2 phos- phorylation had a minimal effect on the growth stimulation of leptin in HEL cells (Fig. 4B). These results suggest that activation of STAT is upstream of the activation of the ERK1/2 pathway, and activation of STAT3 is the major pathway involved in the cell proliferative effect of leptin in HEL cells.

Effect of $O B-R$ inhibition with RNAi on the proliferative effect of leptin on HEL cells. RNAi for OB-R was transfected into HEL cells leading to a drastic decrease in OB-R mRNA 


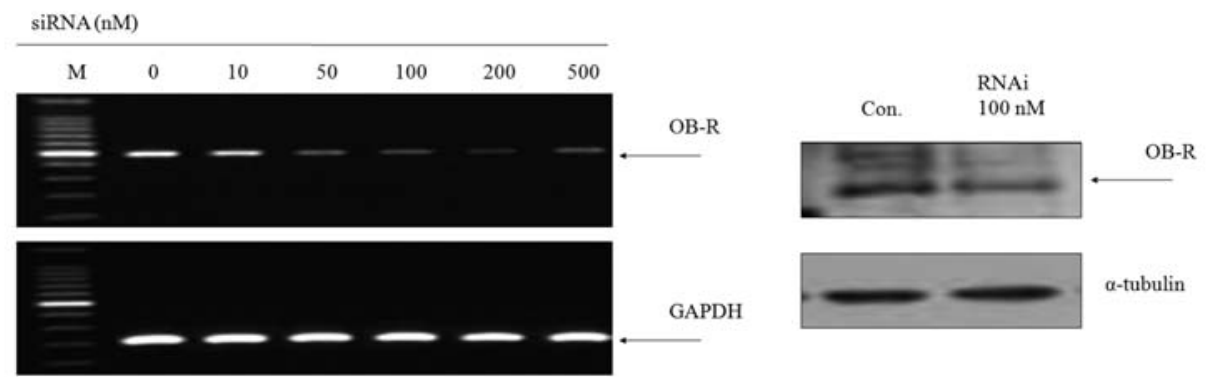

B

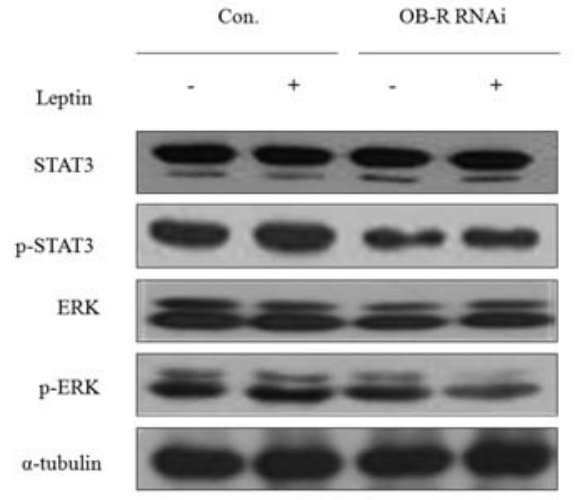

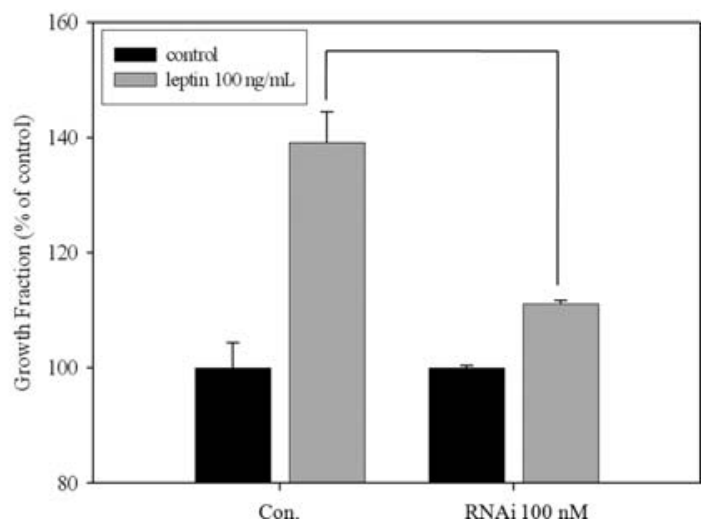

Figure 5. Effect of OB-R inhibition with RNAi on the proliferative effect of leptin on HEL cells. HEL cells were transfected with $100 \mathrm{nM}$ of RNAi for $24 \mathrm{~h}$. Total RNA was extracted from transfected HEL cells and analyzed using reverse transcription-PCR, and total proteins of the transfected HEL cells were examined by immunoblot analysis using a goat polyclonal antibody against OB-R (A). HEL cells were transfected with $100 \mathrm{nM}$ of RNAi or not for $24 \mathrm{~h}$, and then treated with or without $100 \mathrm{ng} / \mathrm{ml}$ of leptin for $2 \mathrm{~h}$. Lysates (15-30 $\mu \mathrm{g}$ of protein) were immunoblotted with specific antibodies against the total and phosphorylated form (p) of STAT3 and ERK1/2 (B) or incubated with $100 \mathrm{ng} / \mathrm{ml}$ of leptin for $72 \mathrm{~h}$, and colorimetric MTT assays then were performed (C). Bars indicate the means $\pm \mathrm{SD} ;(\mathrm{P}<0.05)$.

expression (Fig. 5A). Transfection of specific RNAi did not affect the expression levels of unrelated genes such as GAPDH. As shown in Fig. 5B, RNAi blocked the leptininduced phosphorylation of STAT3 and phosphorylation of ERK1/2, but did not affect the expression of total STAT3 and total ERK1/2. Examination of the cell proliferation in these treatment conditions showed that the blocking of OB-R significantly reduced the growth stimulation of HEL cells by leptin (Fig. 5C).

\section{Discussion}

Leptin is a cytokine mainly produced by adipose tissue. Leptin has been previously reported to stimulate the proliferation of various cell types (20-24) and is considered to be a novel growth factor. However, the role of leptin in acute myelogenous leukemia (AML) cells has never been elucidated. Thus, in the present study, the expression of leptin receptors in human myelogenous leukemia cell lines was investigated using RT-PCR and Western blot analysis. Both short and long isoforms of leptin receptors were observed in all 9 cell lines, suggesting that leptin may play a role via these leptin receptors in leukemia cells. In addition, the effects of leptin treatment resulted in the cell growth of HEL, while the other AML cell lines, KG1, ML1, NB4 and U937, exhibited no significant difference in cell proliferation. In addition, K562 cells (chronic myelogenous leukemia cell line) that expressed a high level of leptin receptor did not exhibit any cell proliferative effect by leptin. These results suggest that, despite the presence of its receptors, leptin may not have a significant proliferate effect on all AML cells apart from HEL cells. However, the minor leptin-induced proliferation of AML cells, apart from HEL, might have been due to the serum-free condition of our cell cuture system. Therefore, further study using leukemic cells from AML patients is needed to confirm the role of leptin in AML.

To elucidate the signaling pathways involved in the leptin-induced cell growth in HEL cells, which exhibited the highest expression of the leptin receptor and was highly proliferated by leptin, we examined the effect of leptin on the activation of the STAT-AKT-ERK pathway. We found that leptin stimulated the STATs and induced the phosphorylation of ERK1/2 but not AKT. In addition, the blocking of OB-R with specific RNAi significantly reduced, not only the activation of both STAT3 and ERK1/2, but also leptin-induced cell proliferation. Growth factors have been known to induce the phosphorylation of STAT1 and $5(25,26)$, and leptin has been known to activate STAT3, 5 and 6 in metabolic disease $(18,27)$. In the present study, we demonstrated that leptin treatment of HEL cells activated STAT3, 5 and 6, but not STAT1 and 2. It has been reported that STAT3 forms heterodimers with STAT1 (28); however, our data showed that STAT1 was not altered by leptin, and STAT3 activated homodimer forms, suggesting that the leptin signaling 
pathway of AML might be different from that of metabolic diseases including diabetes.

Importantly, we report that prevention of leptin-induced activation of STAT with chemical inhibitors significantly reduced the phosphorylation of ERK1/2 and proliferation of HEL cells, indicating that STAT3 might act upstream of ERK1/2, and might be essential for the cell proliferative effect of leptin in HEL cells.

In summary, this study contributes to the understanding of the molecular mechanisms of leptin action in AML cells. Blocking of the leptin receptor might be a novel therapeutic strategy for human acute myelogenous leukemia.

\section{Acknowledgements}

This research was supported by the research fund of Hanyang University (HY-2007-N).

\section{References}

1. Zhang Y, Proenca R, Maffei M, Barone M, Leopold L and Friedman JM: Positional cloning of the mouse obese gene and its human homologue. Nature 372: 425-432, 1994.

2. Campfield LA, Smith FJ, Guisez Y, Devos R and Burn P: Recombinant mouse OB protein: evidence for a peripheral signal linking adiposity and central neural networks. Science 269: 546-549, 1995.

3. Halaas JL, Gajiwala KS, Maffei M, et al: Weight-reducing effects of the plasma protein encoded by the obese gene. Science 269: 543-546, 1995.

4. Friedman JM and Halaas JL: Leptin and the regulation of body weight in mammals. Nature 395: 763-770, 1998.

5. Cioffi JA, Shafer AW, Zupancic TJ, Smith-Gbur J, Mikhail A, Platika D and Snodgrass HR: Novel B219/OB receptor isoforms: possible role of leptin in hematopoiesis and reproduction. Nat Med 2: 585-589, 1996.

6. Bennett BD, Solar GP, Yuan JQ, Mathias J, Thomas GR and Matthews W: A role for leptin and its cognate receptor in hematopoiesis. Curr Biol 6: 1170-1180, 1996.

7. Bouloumie A, Drexler HC, Lafontan M and Busse R: Leptin, the product of $\mathrm{Ob}$ gene, promotes angiogenesis. Circ Res 83: 1059-1066, 1998.

8. Loffreda S, Yang SQ, Lin HZ, et al: Leptin regulates proinflammatory immune responses. FASEB J 12: 57-65, 1998.

9. Janik JE, Curti BD, Considine RV, et al: Interleukin 1 alpha increases serum leptin concentrations in humans. J Clin Endocrinol Metab 82: 3084-3086, 1997.

10. Hoggard N, Hunter L, Trayhurn P, Williams LM and Mercer JG: Leptin and reproduction. Proc Nutr Soc 57: 421-427, 1998.

11. Kieffer TJ, Heller RS, Leech CA, Holz GG and Habener JF: Leptin suppression of insulin secretion by the activation of ATP-sensitive $\mathrm{K}^{+}$channels in pancreatic beta-cells. Diabetes 46: 1087-1093, 1997.
12. Tartaglia LA, Dembski M, Weng X, et al: Identification and expression cloning of a leptin receptor, OB-R. Cell 83: 1263-1271, 1995.

13. Gearing DP, Thut CJ, VandeBos T, et al: Leukemia inhibitory factor receptor is structurally related to the IL-6 signal transducer, gp130. EMBO J 10: 2839-2848, 1991.

14. Hibi M, Murakami M, Saito M, Hirano T, Taga T and Kishimoto T: Molecular cloning and expression of an IL-6 signal transducer, gp130. Cell 63: 1149-1157, 1990.

15. Lee GH, Proenca R, Montez JM, Carroll KM, Darvishzadeh JG, Lee JI and Friedman JM: Abnormal splicing of the leptin receptor in diabetic mice. Nature 379: 632-635, 1996.

16. Baumann H, Morella KK, White DW, et al: The full-length leptin receptor has signaling capabilities of interleukin 6-type cytokine receptors. Proc Natl Acad Sci USA 93: 8374-8378, 1996.

17. Bjorbaek C, Uotani S, da Silva B and Flier JS: Divergent signaling capacities of the long and short isoforms of the leptin receptor. J Biol Chem 272: 32686-32695, 1997.

18. Ghilardi N, Ziegler S, Wiestner A, Stoffel R, Heim MH and Skoda RC: Defective STAT signaling by the leptin receptor in diabetic mice. Proc Natl Acad Sci USA 93: 6231-6235, 1996.

19. Wang Y, Kuropatwinski KK, White DW, Hawley TS, Hawley RG, Tartaglia LA and Baumann H: Leptin receptor action in hepatic cells. J Biol Chem 272: 16216-16223, 1997.

20. Pai R, Lin C, Tran T and Tarnawski A: Leptin activates STAT and ERK2 pathways and induces gastric cancer cell proliferation. Biochem Biophys Res Commun 331: 984-992, 2005.

21. Somasundar P, Frankenberry KA, Skinner H, et al: Prostate cancer cell proliferation is influenced by leptin. J Surg Res 118: 71-82, 2004.

22. Somasundar P, Yu AK, Vona-Davis L and McFadden DW: Differential effects of leptin on cancer in vitro. J Surg Res 113: 50-55, 2003.

23. Konopleva M, Mikhail A, Estrov Z, et al: Expression and function of leptin receptor isoforms in myeloid leukemia and myelodysplastic syndromes: proliferative and anti-apoptotic activities. Blood 93: 1668-1676, 1999.

24. Hardwick JC, Van Den Brink GR, Offerhaus GJ, Van Deventer SJ and Peppelenbosch MP: Leptin is a growth factor for colonic epithelial cells. Gastroenterology 121: 79-90, 2001.

25. Meraz MA, White JM, Sheehan KC, et al: Targeted disruption of the Stat 1 gene in mice reveals unexpected physiologic specificity in the JAK-STAT signaling pathway. Cell 84: 431-442, 1996.

26. Ihle JN: Cytokine receptor signalling. Nature 377: 591-594, 1995 .

27. Darnell JE Jr: Reflections on STAT3, STAT5, and STAT6 as fat STATs. Proc Natl Acad Sci USA 93: 6221-6224, 1996.

28. Schindler C and Darnell JE Jr: Transcriptional responses to polypeptide ligands: the JAK-STAT pathway. Annu Rev Biochem 64: 621-651, 1995. 